\title{
Application of Genetic Engineering Technologies for the Study of Pituitary Development and Neoplasms
}

\author{
Robert Yoshiyuki Osamura ${ }^{1}$, Shunsuke Miyai ${ }^{1}$, Noboru Egashira ${ }^{1}$, Susumu Takekoshi $^{1}$, \\ Michio Yamazaki ${ }^{2}$, Naoko Sanno ${ }^{2}$ and Akira Teramoto ${ }^{2}$ \\ ${ }^{1}$ Department of Pathology, Tokai University School of Medicine and ${ }^{2}$ Department of Neurosurgery, Nippon Medical School
}

Received June 27, 2003; accepted July 22, 2003

Our studies and review of the literature reported by other investigators indicate the essential use of genetic engineering technology to study the physiologic and pathologic mechanisms of transcription of hormone production and the mechanisms of secretion of appropriate bioactive peptides from the prohormones in the endocrine cells which are equipped with secretory granules.

Key words: pituitary gland, pituitary adenoma, gene transfection, secretory pathway, transcription factor

\section{Introduction}

Pituitary gland development is known to follow certain combinations of transcription factors and co-factors. In rodents, the development and functional differentiation of the pituitary glands are defined by early transcription factors and later function-related transcription factors [23]. The anterior pituitary cells are differentiated into three lineages: GH-PRL-TSH, ACTH (POMC), and FSH/LH lineage, for which Pit-1, NeuroD1-Tpit, SF-1 and GATA2 are the key transcription factors for the development of each cell lineage (Scheme 1). Morphologically, the hormone secreting pituitary cells are known to contain characteristic secretory granules, the key functions of which are the secretory regulation of hormones and post-translational processing (proteolytic digestion) of prohormones, such as proopiomelanocortin (POMC). This post-translational processing is of particular importance for the prohormone to gain its biologic activities. Many proteins which function to transport and exocytotic degranulation have been identified for peptide hormones and synaptic vesicles.

On the other hand, recently developed in vivo genetic engineering technology include transgenic animals (mice and rats), knockout animals (mice and rats), and knockin

Correspondence to: Robert Yoshiyuki Osamura, M.D., Department of Pathology, Tokai University School of Medicine, Boseidai Iseharacity, Kanagawa 259-1193, Japan. animals (mice and rats). In vitro genetic engineering techniques include induction of new gene expression (gene transfection), and suppression of particular gene expression (antisense, ribozyme, siRNA). This review article deals with the study of the development and function of the pituitary cells and pituitary adenomas by the application of the above genetic engineering technologies.

\section{Development and Function of the Pituitary Cells and Pituitary Adenomas Studied by In Vivo and In Vitro Genetic Engineering}

Pituitary adenomas developed in transgenic and knockout animals

Human pituitary adenomas are reported to be divided into clinically functioning and non-functioning adenomas $[17,18]$. The former includes GH producing, PRL producing, TSH producing, ACTH producing, and FSH/LH producing adenomas [20]. In the clinically non-functioning adenomas, it has been reported that the majority of the adenomas are positive for gonadotropin $\alpha$-subunit (SU) or $\beta$-SU. The molecular mechanisms for the human pituitary tumorigenesis has yet to be clarified [21]. GHRH is one factor which has been detected in the GH producing adenomas and has been considered to be tumorigenic (Fig. 1) [13]. Experimentally, GHRH transgenic mice and rats developed pituitary adenomas which produce GH and express Pit-1, the same transcription factor as in human 


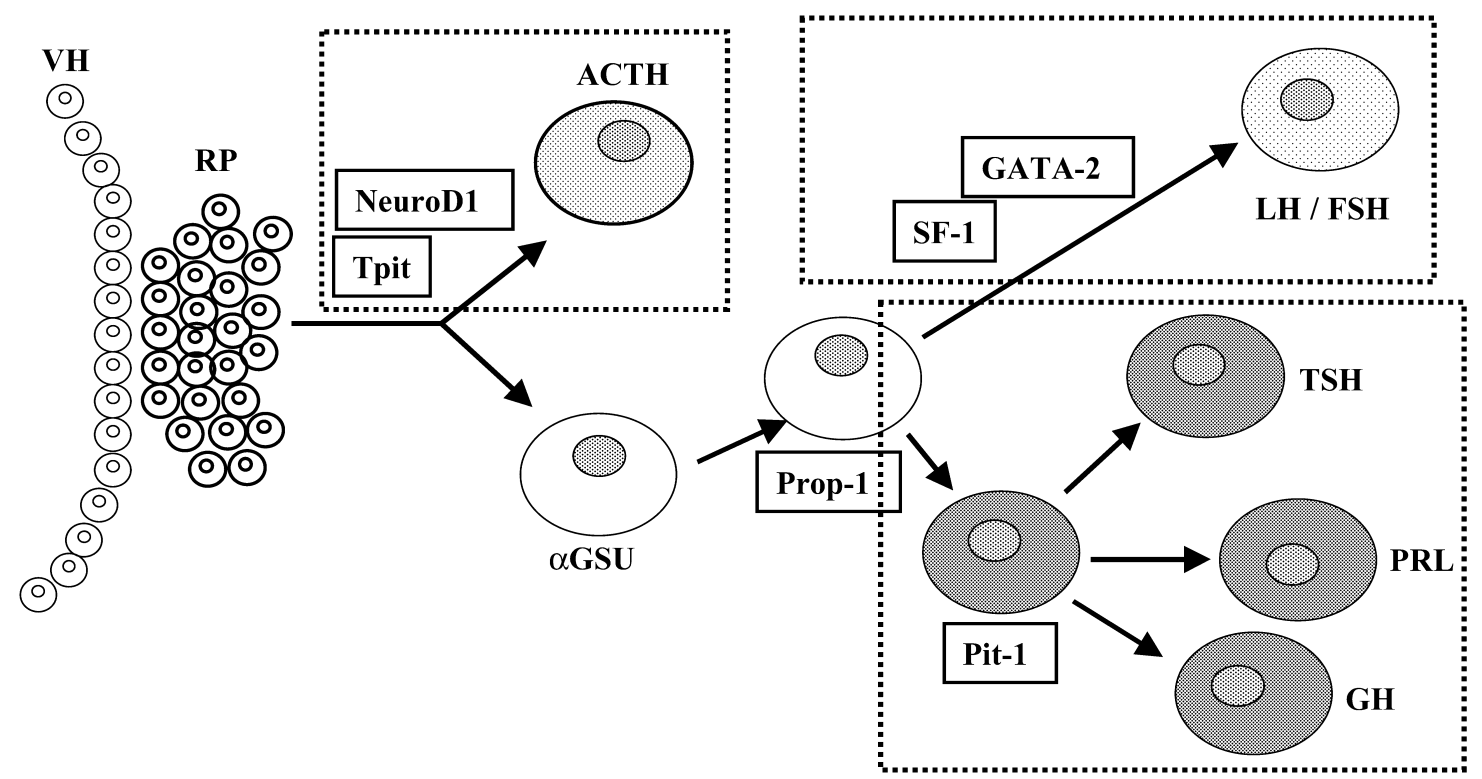

Scheme 1. Pituitary cell lineage. Several transcription factors have been reported to be active in all or a subset of cell lineages, in many cases during a specific period of development. The anterior pituitary cells are well known to be classified into three cell lineages, i.e. GH-PRL-TSH (Pit-1 dependent), POMC (ACTH) (NeuroD1, Tpit dependent) and FSH/LH (SF-1, Dax-1, GATA-2 dependent). VH, ventral hypothalamus; RP, Rathke's pouch.

$\mathbf{a}$

b
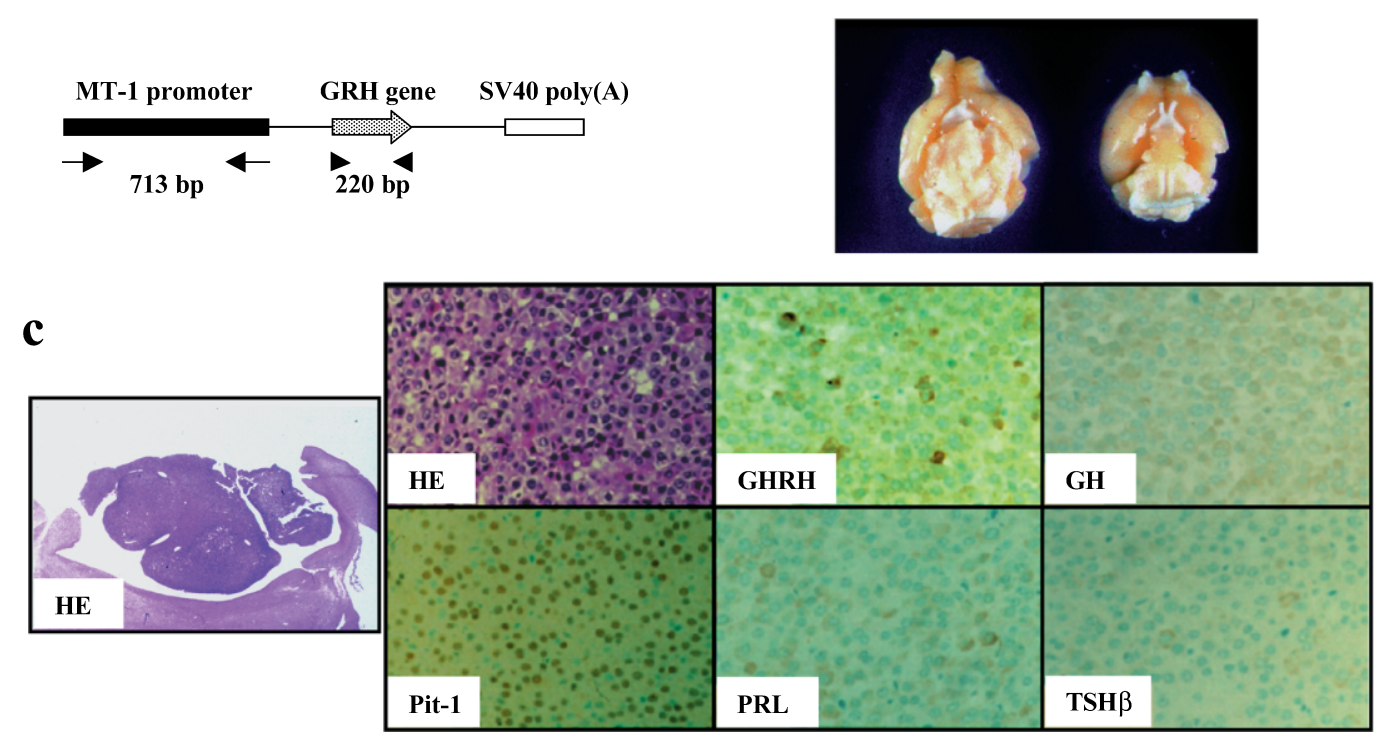

Fig. 1. GHRH transgenic mice (GHRH-Tg) develop pituitary adenomas. (a) Construct of GHRH transgene. The construct consisted of a 713 basepair fragment of the mouse MT-1 promoter, containing elements responsible for metal induction and transcription initiation fused to 220 basepair of the hGHRH gene, encoding the NH2-terminal 31 amino acid signal peptide and the 40 amino acid form of hGHRH. (b) (left) GHRH$\mathrm{Tg}$ had markedly enlarged and congested pituitary gland. (c) Pathological analysis: The pituitary gland is markedly enlarged and multi nodular containing a few adenomas. The induced pituitary adenomas showed the immunohistochemical localization of GHRH, GH, PRL and focal TSH. Pit-1 was diffusely present in the nuclei.

pituitary adenomas. In an experiment in GH deficient rats, GHRH transgene caused pituitary adenomas indicating the oncogenic role of GHRH [1]. Other transgenic animals which develop pituitary tumors include Prop-1 transgenic mice which develop TSH producing or non-functioning pituitary tumors [5]. FGF transgenic mice also induced PRL producing pituitary adenomas $[2,30]$.

On the other hand, deprivation of some factors also induced pituitary tumors. This catergory includes p27 knockout mice which develop PRL and ACTH cell tumors, 
particularly the ACTH (or MSH) producing intermediatelobe derived tumors [14]. Dopamine (D2) receptor knockout mice induce PRL producing pituitary adenomas [9].

\section{Induction of aberrant expression of transcription factors in vitro}

Gene transfection study has been found to be useful to study aberrant expressions of transcription factors and unusual combinations of produced hormones by tumor cells. This example includes the usual combination of $\mathrm{GH}$ and ACTH production in cases of GH producing or ACTH producing adenomas. In these two groups of the adenomas, the combination of $\mathrm{GH}$ and ACTH as produced hormones usually does not occur. We have shown that this pathologic phenomenon depends on the "aberrant" expression of transcription factors, i.e., Pit-1 and NeuroD1 or Tpit [25]. In these pituitary adenomas, the same tumor cells focally contain both GH and ACTH. By immunohistochemistry, the tumor cells express Pit-1 and NeuroD1 in the same tumor cells. In order to prove this working hypothesis, an aberrant combination of transcription factors could be induced by transfection of Pit-1 into ACTH producing mouse AtT-20 cells which results in the production of ACTH and GH in the same cells as was observed in the above human adenomas (Fig. 2). The transfected gene was constructed by fusing Pit-1 and Green Fluorescent Protein (GFP). Thus it was shown that Pit-1 protein was bound to the nuclei in the living cells as GFP could be traced as the fusion protein moved from the cytoplasm and into the cell [12].

\section{Secretion of Pituitary Hormones in Physiologic and Pathologic Conditions Studied by In Vitro Genetic Engineering}

It has been clarified that many peptide hormones are produced as precursor prohormones; for instance, adrenocorticotropic hormone (ACTH) is derived from the prohormone proopiomelaoncortin (POMC) [3]. The proteolytic digestion is designated as "processing of prohormones" and is accomplished by specific enzymes known as prohormone convertases (PC) 1/3 and PC2 [26, 27]. Each prohormone is subjected to processing by the proteolytic digestion at the particular portion such as -lys-lys-, -lys-Arg- [3]. It has been elucidated that $\mathrm{PC} 1 / 3$ and $\mathrm{PC} 2$ are localized in the secretory granules where the specific processing of prohormones takes place [8]. In physiological conditions, prohormones result in smaller bioactive peptide hormones while they are transported intracellularly through regulated pathways via secretory granules [10]. In pathologic conditions, especially in the neoplastic cells, it has been also pointed out that prohormones are secreted from the tumor cells; that is, small cell carcinoma cells produce and secrete POMC [7, 15] or progastrin releasing peptide (GRP) [24]. One of the proposed hypotheses is that these tumor cells lack adequate numbers of secretory granules where post-translational processing should occur.

Experimental models using gene transfection disclosed that the presence of secretory granules is essential for the processing of POMC and supported the proposed mechanism that the human cancer cells secrete prohormones by the lack of adequate secretory granules. The experiment was
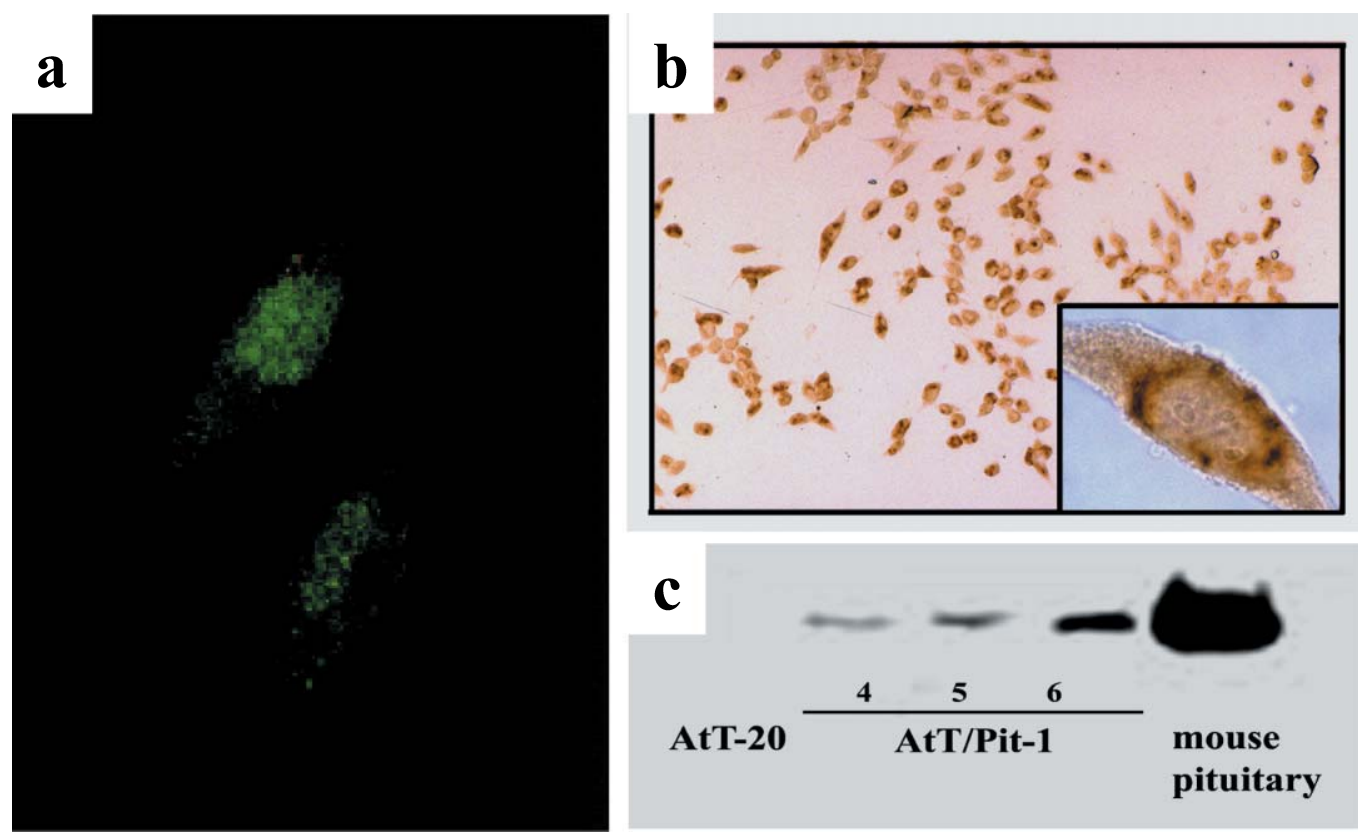

Fig. 2. Induction of aberrant expression of transcription factors in vitro. (a) Visualization of GFP fluorescence in transfected AtT-20 cell line: The transfected gene was constructed by fusing Pit-1 and Green Fluorescent Protein (GFP). Thus it was shown that Pit-1 protein was bound to the nuclei in the living cells as GFP could be traced that the fusion protein moved from the cytoplasm and into the cell. (b) Immunohistochemistry for GH: AtT-20 cells which were transfected GFP-Pit-1 fusion gene expressed GH in cytoplasm near the nuclei. (c) Immunoblot analysis for GH protein: The $22 \mathrm{kDa}$ immunoreactive band was detected in AtT-20 cells transfected with GFP-Pit-1 fusion gene. 
a

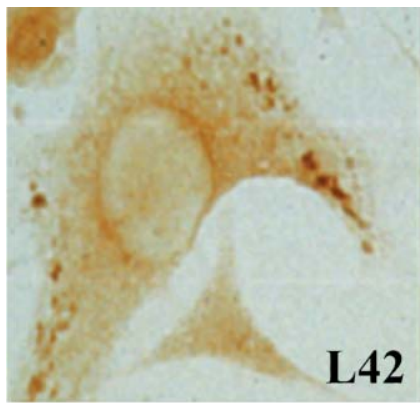

b

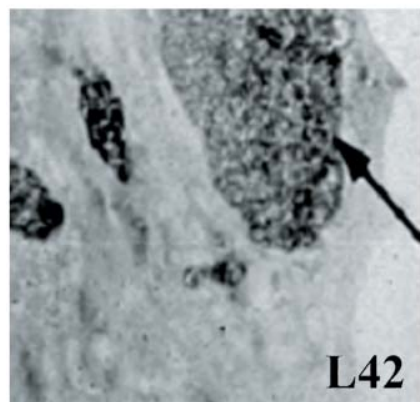

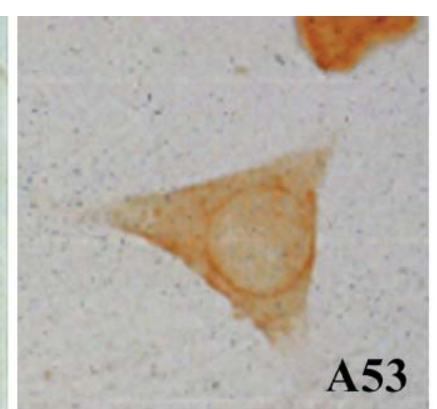

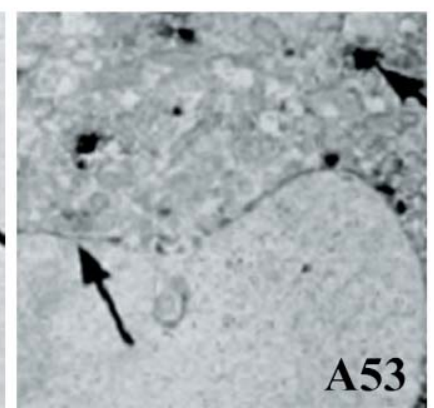

c

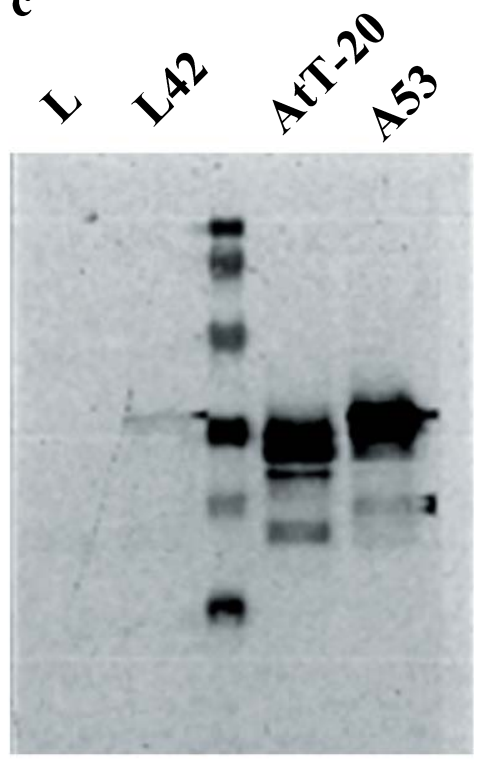

Fig. 3. Transfection of human POMC gene to mouse AtT-20 cells (equipped with endogenous mouse POMC production and secretory granules) and to L cells (fibroblasts without secretory granules). L cell and AtT-20 cells expressing human POMC mRNA, confirmed by Northern blotting, were designated as L42 cells and A53 cells, respectively. (a) Light microscopic immunohistochemical localization; Immunocytochemically, many L42 cells and many A53 cells were positive for human ACTH, POMC NTF and b-LPH. (b) Immunoelectron microscopy; L42 cells showed the localization of POMC in the perinuclear space the cisternae of rough encoplasmic reticula. A53 cells showed the localization of human b-LPH in RER, perinuclear spaces and in scattered secretory granules. (c) Immunoblotting of L42 and A53 cells by anti-ACTH antibody; While A53 cells show an immunoreactive band at the size of 35, 24.5 and $24 \mathrm{kDa}$, L42 cell form a single immunoreactive band at the size of $35 \mathrm{kDa}$.

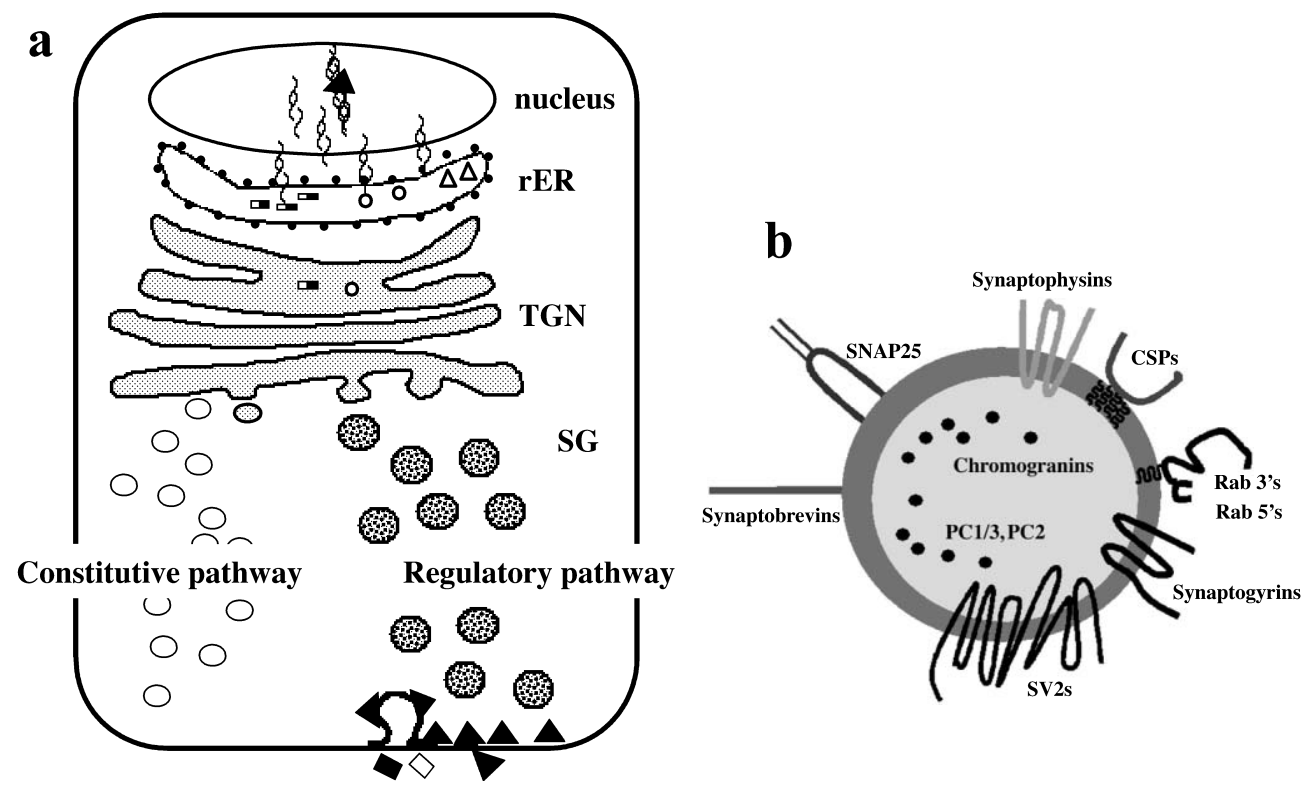

Scheme 2. Secretory pathway and secretory glanules. (a) Secretory pathway: Constitutive and regulated secretory pathways of peptide hormones in secreting cells. rER, roufh endoplasmic reticula; TGN, trans golgi network; SG, secretory granule. (b) Secretory granule: Many proteins have been disclosed in relation to the secretion of the secretory granules.

done by transfecting human POMC gene to mouse AtT-20 cells (equipped with endogenous mouse POMC production and secretory granules) and to $\mathrm{L}$ cells (fibroblasts without secretory granules) (Fig. 3). The transformed L cells secrete POMC and the transformed AtT-20 cells secrete processed human POMC. Immunoelectron microscopic study dis- 
closed that ACTH-immunoreactivity lies in the lumina of rough endoplasmic reticula (RER) but not in the secretory granules in the transformed L cells, and that it was localized in the RER vesicles as well as in the secretory granules in the transformed AtT-20 cells. These results support the view that regulated pathways via secretory granules are essential for the processing of prohormones and that constitutive pathways skipping secretory granules result in prohormones, as occur in some neuroendocrine tumor cells [16].

Recently, many proteins have been disclosed in relation to the secretion of the secretory granules (Scheme 2). Particular proteins designated as SNARES are related to the exocytosis of the secretory granules [4]. Knockout animals can serve as animal models to study the functional role of these proteins $[22,28]$. In the particular endocrine cell lines, antisense or siRNA technologies can be implemented to study the step-by-step mechanism of the transport of secretory granules [11].

On the other hand, transgenic animals of these secretion-related proteins are expected to elucidate the molecular mechanisms of "granulogenesis" [29].

Recent technology using green fluorescence protein (GFP) is expected to study the alteration of secretory mechanisms of the endocrine cells according to the stimulation or suppression of the function, i.e. the sorting of the regulated and constitutive pathways. One major advantage to the other biomarkers lies in its application to viable cells when combined with confocal laser scanning microscope (CLSM). There have been limited numbers of report on the secretory mechanism in live cells $[6,19]$.

\section{References}

1. Asa, S. L., Kovacs, K., Stefaneanu, L., Horvath, E., Billestrup, N., Gonzalez-Manchon, C. and Vale, W. (1992) Pituitary adenomas in mice transgenic for growth hormone-releasing hormone. Endocrinology 131; 2083-2089.

2. Asa, S. L. and Ezzat, S. (2002) The pathogenesis of pituitary tumours. Nat. Rev. Cancer 2; 836-849.

3. Chance, B. (1968) Biological membranes: regulatory functions. Science 160; 1261-1266.

4. Chen, Y. A. and Scheller, R. H. (2001) SNARE-mediated membrane fusion. Nat. Rev. Mol. Cell. Biol. 2; 98-106.

5. Cushman, L. J., Watkins-Chow, D. E., Brinkmeier, M. L., Raetzman, L. T., Radak, A. L., Lloyd, R. V. and Camper, S. A. (2001) Persistent Prop1 expression delays gonadotrope differentiation and enhances pituitary tumor susceptibility. Hum. Mol. Genet. 10; 1141-1153.

6. El Meskini, R., Jin, L., Marx, R., Bruzzaniti, A., Lee, J., Emeson, R. and Mains, R. (2001) A signal sequence is sufficient for green fluorescent protein to be routed to regulated secretory granules. Endocrinology 142; 864-873.

7. Gil Aguado, A., Sanchez Franco, F., Barbado Hernandez, J., Rodriguez Gonzalez, J., Lopez Barea, F., Arnalich Fernandez, F. and Vazquez Rodriguez, J. J. (1979) Hormonal multiplicity of an apudoma of the lung and pancreas. Characterization of the different peptides in the tumoral extracts (author's transl). Med. Clin. (Barc). 72; 242-247.

8. Halban, P. A. and Irminger, J. C. (1994) Sorting and processing of secretory proteins. Biochem. J. 299; 1-18.

9. Hentges, S. T. and Low, M. J. (2002) Ovarian dependence for pituitary tumorigenesis in D2 dopamine receptor-deficient mice. Endocrinology 143; 4536-4543.

10. Kelly, R. B. (1985) Pathways of protein secretion in eukaryotes. Science 230; 25-32.

11. Kim, T., Tao-Cheng, J. H., Eiden, L. E. and Loh, Y. P. (2002) Large dense-core secretory granule biogenesis is under the control of chromogranin A in neuroendocrine cells. Ann. N Y Acad. Sci. 971; 323-331.

12. Kurotani, R., Yoshimura, S., Iwasaki, Y., Inoue, K., Teramoto, A. and Osamura, R. Y. (2002) Exogenous expression of Pit-1 in AtT-20 corticotropic cells induces endogenous growth hormone gene transcription. J. Endocrinol. 172; 477-487.

13. Matsuno, A., Katakami, H., Sanno, N., Ogino, Y., Osamura, R. Y., Matsukura, S., Shimizu, N. and Nagashima, T. (1999) Pituitary somatotroph adenoma producing growth hormone (GH)releasing hormone (GHRH) with an elevated plasma GHRH concentration: a model case for autocrine and paracrine regulation of GH secretion by GHRH. J. Clin. Endocrinol. Metab. 84; 32413247.

14. Nakayama, K., Ishida, N., Shirane, M., Inomata, A., Inoue, T., Shishido, N., Horii, I., Loh, D. Y. and Nakayama, K. (1996) Mice lacking p27(Kip1) display increased body size, multiple organ hyperplasia, retinal dysplasia, and pituitary tumors. Cell 85 ; $707-$ 720.

15. Orth, D. N., Guillemin, R., Ling, N. and Nicholson, W. E. (1978) Immunoreactive endorphins, lipotropins and corticotropins in a human nonpituitary tumor: evidence for a common precursor. J. Clin. Endocrinol. Metab. 46; 849-852.

16. Osamura, R. Y., Suemizu, Y., Yoshimura, S., Hori, S., Inada, K., Watanabe, K., Nakai, Y. and Imura, H. (1991) Secretory pathways and processing of human proopiomelanocortin (POMC) using transformed mouse cultured fibroblasts (L cells) and AtT20 cells by human POMC gene-preembedding immunoelectron microscopic studies. Peptides 12; 503-507.

17. Osamura, R. Y., Tahara, S., Sanno, N., Kurotani, R. and Teramoto, A. (1998) Mechanism of hormone production in pituitary cells and pituitary neoplasms; synergistic actions of transcription factors. Acta Histochem. Cytochem. 32; 107-110.

18. Osamura, R. Y., Tahara, S., Kurotani, R., Sanno, N., Matsuno, A. and Teramoto, A. (2000) Contributions of immunohistochemistry and in situ hybridization to the functional analysis of pituitary adenomas. J. Histochem. Cytochem. 48; 445-458.

19. Pouli, A. E., Kennedy, H. J., Schofield, J. G. and Rutter, G. A. (1998) Insulin targeting to the regulated secretory pathway after fusion with green fluorescent protein and firefly luciferase. Biochem J. 331; 669-675.

20. Sanno, N., Tahara, S., Kurotani, R., Matsuno, A., Teramoto, A. and Osamura, R. Y. (2001) Cytochemical and molecular biological aspects of the pituitary and pituitary adenomas - cell differentiation and transcription factors. Prog. Histochem. Cytochem. 36; 263-299.

21. Sanno, N., Teramoto, A., Osamura, R. Y., Horvath, E., Kovacs, K., Lloyd, R. V. and Scheithauer, B. W. (2003) Pathology of pituitary tumors. Neurosurg. Clin. N Am. 14; 25-39.

22. Schoch, S., Deak, F., Konigstorfer, A., Mozhayeva, M., Sara, Y., Sudhof, T. C. and Kavalali, E. T. (2001) SNARE function analyzed in synaptobrevin/VAMP knockout mice. Science 294; 1117-1122.

23. Scully, K. M. and Rosenfeld, M. G. (2002) Pituitary development: regulatory codes in mammalian organogenesis. Science 295; 2231-2235.

24. Stieber, P., Dienemann, H., Schalhorn, A., Schmitt, U. M., Reinmiedl, J., Hofmann, K. and Yamaguchi, K. (1999) Progastrin-releasing peptide (ProGRP) - a useful marker in small cell lung carcinomas. Anticancer Res. 19; 2673-2678.

25. Tahara, S., Kurotani, R., Ishii, Y., Sanno, N., Teramoto, A. and Osamura, R. Y. (2002) A case of Cushing's disease caused by 
pituitary adenoma producing adrenocorticotropic hormone and growth hormone concomitantly: aberrant expression of transcription factors NeuroD1 and Pit-1 as a proposed mechanism. Mod. Pathol. 15; 1102-1105.

26. Tanaka, S. and Kurosumi, K. (1992) A certain step of proteolytic processing of proopiomelanocortin occurs during the transition between two distinct stages of secretory granule maturation in rat anterior pituitary corticotrophs. Endocrinology 131; 779-786.

27. Thomas, L., Leduc, R., Thorne, B. A., Smeekens, S. P., Steiner, D. F. and Thomas, G. (1991) Kex2-like endoproteases PC2 and PC3 accurately cleave a model prohormone in mammalian cells: evidence for a common core of neuroendocrine processing enzymes. Proc. Natl. Acad. Sci. U S A 88; 5297-5301.
28. Washbourne, P., Thompson, P. M., Carta, M., Costa, E. T., Mathews, J. R., Lopez-Bendito, G., Molnar, Z., Becher, M. W., Valenzuela, C. F., Partridge, L. D. and Wilson, M. C. (2002) Genetic ablation of the t-SNARE SNAP-25 distinguishes mechanisms of neuroexocytosis. Nat. Neurosci. 5; 19-26.

29. Yaekura, K., Julyan, R., Wicksteed, B. L., Hays, L. B., Alarcon, C., Sommers, S., Poitout, V., Baskin, D. G., Wang, Y., Philipson, L. H. and Rhodes, C. J. (2003) Insulin secretory deficiency and glucose intolerance in Rab3A null mice. J. Biol. Chem. 278; 9715-9721.

30. Yu, S., Asa, S. L. and Ezzat, S. (2002) Fibroblast growth factor receptor 4 is a target for the zinc-finger transcription factor Ikaros in the pituitary. Mol. Endocrinol. 16; 1069-1078. 